\title{
Rabies in Costa Rica: Documentation of the Surveillance Program and the Endemic Situation from 1985 to 2014
}

\author{
Sabine E. Hutter, ${ }^{1}$ Katharina Brugger, ${ }^{1}$ Victor Hugo Sancho Vargas, Rocío González, \\ Olga Aguilar, Bernal León,, Alexander Tichy, ${ }^{3}$ Clair L. Firth,, and Franz Rubel ${ }^{1}$
}

\begin{abstract}
This is the first comprehensive epidemiological analysis of rabies in Costa Rica. We characterized the occurrence of the disease and demonstrated its endemic nature in this country. In Costa Rica, as in other countries in Latin America, hematophagous vampire bats are the primary wildlife vectors transmitting the rabies virus to cattle herds. Between 1985 and 2014, a total of 78 outbreaks of bovine rabies was reported in Costa Rica, with documented cases of 723 dead cattle. Of cattle outbreaks, $82 \%$ occurred between 0 and 500 meters above sea level, and seasonality could be demonstrated on the Pacific side of the country, with significantly more outbreaks occurring during the wet season. A total of 1588 animal samples, or an average of 55 samples per year, was received by the veterinary authority (SENASA) for rabies diagnostic testing at this time. Of all samples tested, 9\% (143/1588) were positive. Of these, $85.6 \%(125 / 1588)$ were from cattle; four dogs $(0.3 \%$ [4/1588]) were diagnosed with rabies in this 30-year period. Simultaneously, an extremely low number $(n=3)$ of autochthonous rabies cases were reported among human patients, all of which were fatal. However, given the virus' zoonotic characteristics and predominantly fatal outcome among both cattle and humans, it is extremely important for healthcare practitioners and veterinarians to be aware of the importance of adequate wound hygiene and postexpositional rabies prophylaxis when dealing with both wild and domestic animal bites.
\end{abstract}

Key Words: Bats—Cattle—Rabies_-Vector-Zoonosis.

\section{Introduction}

$\mathbf{R}$ ABIES IS A MAJOR NEGLECTED VIRAL ZOONOSIS (Rupprecht and Kuzmin 2015), which kills tens of thousands of people each year (WHO 2013). Bovine rabies is the most frequently diagnosed type of the disease in Costa Rica and considered a potential risk of transmission to humans (McDaniel et al. 2014).

In Latin America, dog bites and contact with wildlife, in particular hematophagous bats, are the main sources of infection for humans and livestock (Belotto et al. 2005). While the role of dogs in rabies transmission has decreased in this region, from a maximum of 6716 canine cases in 1993 to 1311 cases in 2002 (Belotto et al. 2005), the common vampire bat (Desmodus rotundus) is still the major reservoir and vector of rabies virus (Loza-Rubio et al. 1999, Ellison et al. 2014). These bats, which occur only in Latin America from Mexico to Argentina, Chile, and Uruguay (McNab 1973), prefer to take a blood meal from cattle or equids (Voigt and Kelm 2006) and, in doing so, can transmit rabies virus. Cattle are dead-end hosts: rabies virus in bovines causes the paralytical form and is almost always fatal in this species (Mayen 2003, Johnson et al. 2014). The economic burden on the livestock industry is considerable (Belotto et al. 2005, Johnson et al. 2014). Apart from cattle mortality due to rabies, profits from livestock production are also reduced by bat bites through damage to hides, weight loss, and decreased milk production (Anderson et al. 2014).

In the 1980s, the Costa Rican Veterinary Authority, SENASA (Servicio Nacional de Salud Animal), established a

\footnotetext{
${ }^{1}$ Institute of Veterinary Public Health, University of Veterinary Medicine, Vienna, Austria.

${ }^{2}$ Servicio Nacional de Salud Animal (SENASA), Heredia, Costa Rica.

${ }^{3}$ Department of Biomedical Sciences, University of Veterinary Medicine, Vienna, Austria.
}

(c) Sabine E. Hutter et al., 2016; Published by Mary Ann Liebert, Inc. This Open Access article is distributed under the terms of the Creative Commons Attribution Noncommercial License (http://creativecommons.org/licenses/by-nc/4.0/) which permits any noncommercial use, distribution, and reproduction in any medium, provided the original author(s) and the source are credited. 
national animal rabies surveillance and control program. Evaluating this animal health surveillance system as defined by Hoinville et al. (2013), the program could be described as enhanced passive syndromic surveillance to provide control measures as soon as a rabies case is detected. It initially relied on farmers of cattle suspected to be infected with rabies notifying the veterinary authorities. Surveillance today is still compulsory and includes cattle, horses, small ruminants, pigs, dogs, cats, or wild animals with neurological signs. Once the SENASA laboratory confirms a rabies diagnosis, disease mitigation measures are initiated. These measures consist of informing local inhabitants of the presence of the virus and preventing its spread by means of free vaccinations for cattle and other susceptible domestic animals around the outbreak area. In addition, bats are captured in mist nets and coated with a slow-acting topical anticoagulant poison. They are then released to fly back to their roosts to reduce the local bat population (Lord 1980, Johnson et al. 2014). These measures are similar in most Latin American countries (Streicker et al. 2012). People thought to have been exposed to the virus are vaccinated by the Costa Rican Ministry of Health (Ministerio de Salud). There have been no reports of rabies transmission from cattle to humans during the last 30 years. The last autochthonous human rabies cases in 2001 and 2014 were epidemiologically linked to various animals, but were subsequently determined to have been caused by bat-associated virus strains (Badilla et al. 2003, Ministerio de Salud 2014).

Despite its enzootic and recurring nature, no comprehensive epidemiological analyses on Costa Rican bovine rabies data have been published so far. Therefore, the aim of this study was to determine where outbreaks occurred, whether they were seasonal or showed a certain periodicity, and if they related to cattle density or occurred more frequently at certain altitudes.

\section{Materials and Methods}

\section{Study area}

Costa Rica is a country in Central America with a surface area of $51,100 \mathrm{~km}^{2}$ (Fig. 1). A mountain range, which reaches from the northwest to the southeast of the country and in- cludes several major volcanoes and mountains up to 3800 meters altitude, separates the coastal planes on both the Atlantic (Caribbean Sea) and Pacific Ocean. Costa Rica is one of the most biodiverse countries in the world, maintaining a fourth of its land area for conservation (IUCN and UNEPWCMC 2014).

According to the agricultural holdings database (SIREA), there are around 2 million cattle on 53,000 farms in Costa Rica (SENASA 2014). The cattle industry is focused on meat production with pure and European Zebu-cross cattle in the lowlands and dairy production with European breeds in the cooler mountainous regions. Although Costa Rica is best known for its tropical fruit and coffee production, $28.5 \%$ of farms keep cattle as their main activity (INEC 2015).

\section{Rabies datasets 1985-2014}

Rabies outbreaks have been documented by the SENASA rabies surveillance program since 1985 . The epidemiological outbreak database includes the date of the outbreak, the number and species of dead animals attributed to rabies, and also the georeferenced location for most of the outbreaks. The annual reports of the national SENASA rabies program additionally include information on the number of vaccinated animals, bat captures, and other activities, such as publicity campaigns.

For outbreaks where georeferencing was not available, missing coordinates were added using the farm identification number and the SIREA database. If the farm could not be found in SIREA, coordinates were assigned as the central point of the given district or village and estimated using Google Earth and geospacial vector data of the geopolitical division of Costa Rica.

Detailed information on rabies diagnostic testing is available from the laboratory database. This database contains information on the number of analyzed samples, as well as the species sampled, the date of analysis (entry and/or result date), approximate or exact location, and the result for each sample. From 1981 until 1993, brain samples were analyzed using Sellers staining to detect Negri bodies; from 1993 onward, immunofluorescence testing and mouse inoculation replaced the older method. In 2013, PCR analysis and
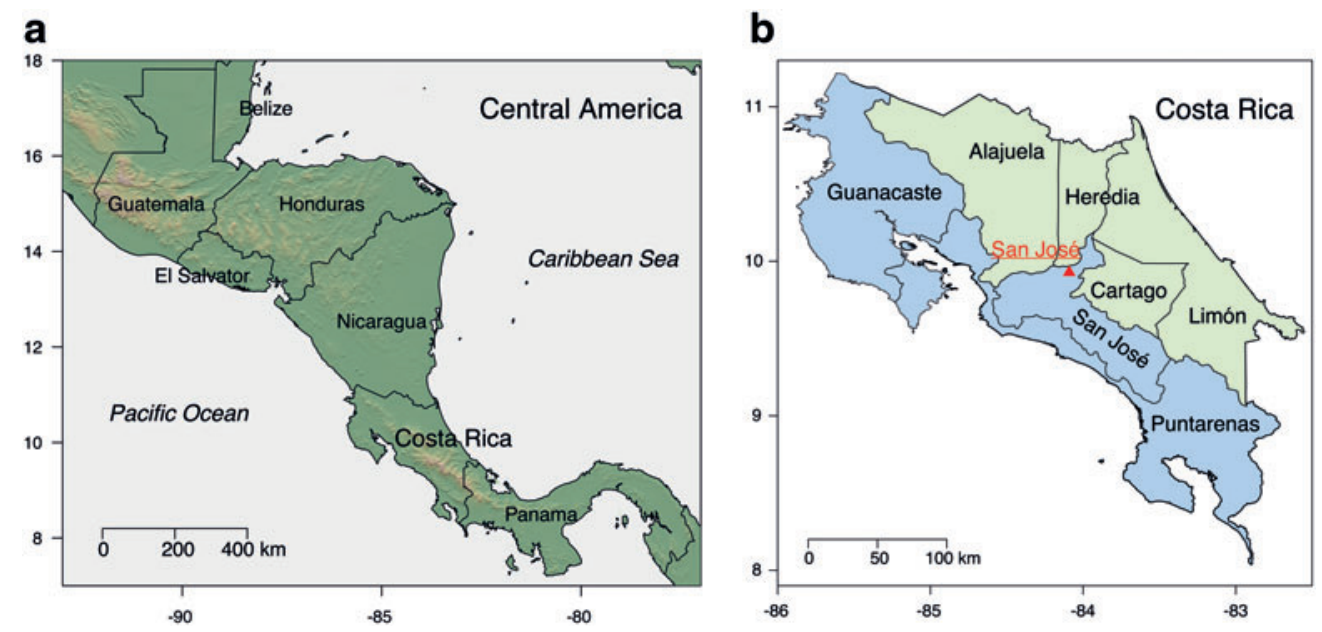

FIG. 1. (a) Costa Rica is located on the Central American isthmus; (b) shows the country with its seven provinces divided into a Pacific (light blue) and an Atlantic-Caribbean (light green) region according to rainfall patterns. Color images available online at www.liebertpub.com/vbz 


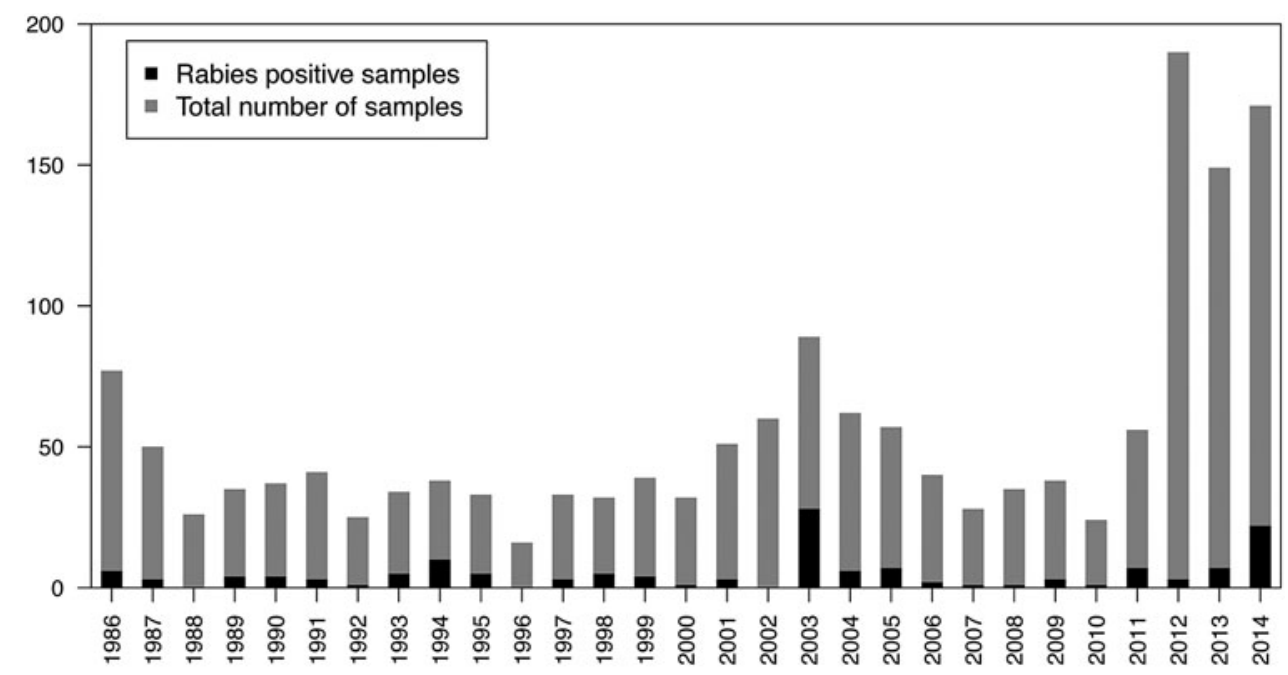

FIG. 2. Total number and positive animal rabies samples between 1986-2014.

sequencing were added to the palette of available methods: for sequencing, a fragment of $\sim 1500 \mathrm{bp}$, which includes the complete nucleoprotein gene, is amplified and sequenced with the RAB20 5'-ACGCTTAACAACAARATCARAG-3' and RAB304 5'-TTGACGAAGATCTTGCTCAT-3' primers. A sequencing PCR is then carried out and the samples are analyzed in a 3130 ABI genetic analyzer.

The main objective of this article is to analyze the rabies situation in Costa Rica. For our analysis of bovine rabies, we defined an outbreak as follows: "A laboratory-confirmed event of bovine rabies, in which one or more cattle were infected and died within a $5 \mathrm{~km}$ radius and/or within 6 months from the result date of the first laboratory-confirmed case." Vampire bats are known to be relatively sedentary (Trajano 1996), with a flight radius of around $3 \mathrm{~km}$ or less (Young 1971, Delprieto et al. 1992). The $5 \mathrm{~km}$ radius used here, as well as the 6-month period, was chosen arbitrarily with the intention of excluding outbreaks from the same source (vampire bat roost).

\section{Additional datasets}

Using the SIREA database, the number of cattle, production type, and the georeferenced location of all cattle farms in Costa Rica were available. In addition, we extracted the altitude in meters above sea level for each farm from the WorldClim database (Hijmans et al. 2005).

Reported sightings of $D$. rotundus bats in Costa Rica were obtained from the Global Biodiversity Information Facility (GBIF 2015). After deleting duplicates and implausible reports, 71 observations remained.

\section{Statistical analysis}

Descriptive analyses were performed for laboratoryconfirmed rabies cases and outbreaks. At first, the distribution of rabies cases by species was analyzed from the laboratory database. A time series plot was created to compare total versus positive samples.

Since the SENASA rabies program focuses on animals, human cases were analyzed separately, with focus on the number of fatalities and the year and origin of infection.

The main focus was given to cattle outbreaks, which were plotted on a map to illustrate their temporal and geographical distribution. Annual outbreaks within the 30-year period were outlined to depict potential outbreak patterns. The yearly number of outbreaks was squared and 4-year moving averages were used to investigate periodicity in the outbreak pattern.

A Pearson correlation was performed at both provincial and cantonal level to test whether there was a statistical association between cattle density and the number of outbreaks.

The climate in Costa Rica can very generally be divided into an Atlantic region with rainfalls almost all year around and a Pacific region with two marked seasons (rainy and dry; Instituto Metereológico Nacional 2008). We separated the provinces arbitrarily according to these rainfall patterns. Goodness-of-fit chi-square test with Yates correction was performed to analyze seasonality.

All analyses were conducted using Excel (Microsoft) and the open-source statistical software R (R Core Team 2014).

\section{Results}

\section{Human and animal rabies cases in Costa Rica between 1986 and 2014}

The laboratory database contains information on animal species tested for rabies since 1986. A total of 1588 animal

Table 1. Analysis of All Rabies Tests in Animal Species Between 1986 AND 2014

\begin{tabular}{lrrrc}
\hline Species tested & \multicolumn{3}{c}{$\begin{array}{c}\text { Total } \\
\text { Positive }\end{array}$} & $\begin{array}{c}\text { Positive of } \\
\text { total (\%) }\end{array}$ \\
\hline Cattle & 125 & 1009 & 1197 & 7.9 \\
Dogs & 4 & 147 & 157 & 0.3 \\
Bats & 3 & 68 & 72 & 0.2 \\
Horses & 2 & 44 & 49 & 0.1 \\
Pigs & 1 & 3 & 4 & 0.1 \\
Other wild animals & 1 & 14 & 16 & 0.1 \\
Cats & 0 & 22 & 23 & 0 \\
Small ruminants & 0 & 9 & 11 & 0 \\
Other domesticated & 0 & 7 & 7 & 0 \\
$\quad$ animals & & & & \\
Raccoons & 0 & 5 & 5 & 0 \\
Rodents & 0 & 28 & 28 & 0 \\
Species not given & 6 & 13 & 19 & 0.4 \\
Total & 143 & 1369 & 1588 & 9.0 \\
\hline
\end{tabular}


FIG. 3. Geo-referenced outbreaks of bovine rabies (colored dots) between 19852014 and cattle density on farms (gray dots) in Costa Rica. Color images available online at www.liebertpub.com/vbz

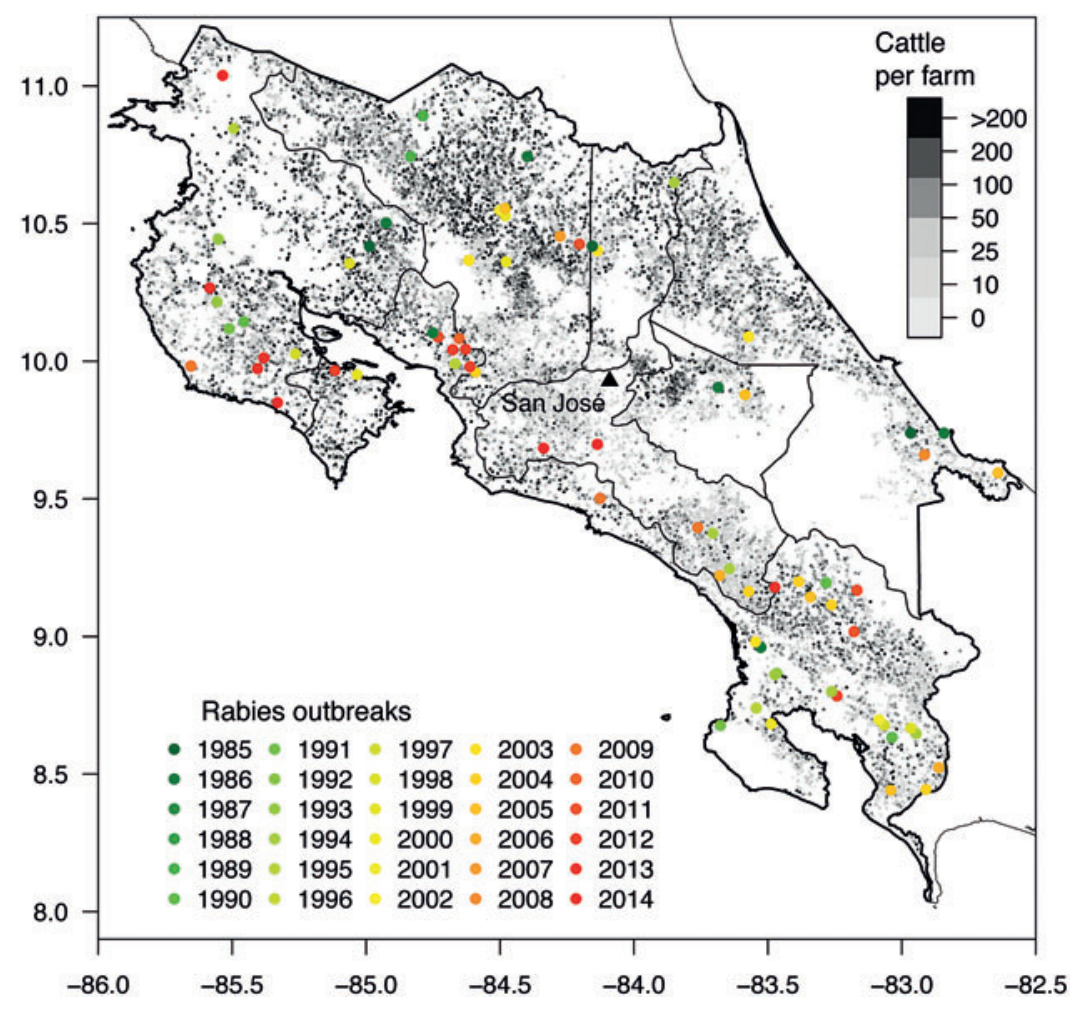

samples were tested for rabies between 1986 and 2014 (Fig. 2). Most samples (75.4\%) were of bovine origin, followed by dogs $(9.9 \%)$ and bats (4.5\%; Table 1). Of all samples tested, 9\% (143/1588) were positive. Of these, $85.6 \%(125 / 1588)$ were from cattle. SENASA performed phylogenetic analysis on the four cattle rabies outbreaks from 2014, and it was determined that three originated from $D$. rotundus strains (Genbank ${ }^{\circledR}$ accession numbers KU550099, KU550100 and KU550102) and the fourth one from a strain commonly found in Tadarida brasiliensis (KU550101), an insectivorous bat species. In this outbreak, which was the most northerly in the country (Fig. 3, red dot close to the Nicaraguan border), only one animal was diagnosed.

Four dogs were diagnosed with rabies in this period: two canine rabies cases occurred in the province of Guanacaste in 1987, close to the Nicaraguan border, and were declared to be imported cases; one occurred in the province of Alajuela in 1999; and the last one occurred in the province of Puntarenas in 2014. Information on the virus strain is only available for this latter case, which was determined to be associated with a D. rotundus strain.

Human samples are also analyzed at the SENASA laboratory, which is the only official rabies laboratory in the country. Of the five human fatalities (Table 2), three were attributed to autochthonous rabies and two are believed to have been infected abroad (Nicaragua). The last autochthonous case in 2014 concerned a boy and his dog (mentioned above), which are believed to have both been infected through the bite of a squirrel (genus: Sciurus) (Genbank accession numbers KU550098 and KU550097, respectively). The last imported case in 2014 concerned a girl from Nicaragua, who was infected with a dog rabies strain (KU550103).

\section{Bovine rabies in Costa Rica}

Between 1985 and 2014, a total of 78 outbreaks of bovine rabies was reported in Costa Rica, with 723 dead cattle documented. Vaccinations were administered on the outbreak and surrounding farms, with $~ 5300$ vaccine doses applied per year. Laboratory confirmation for the presence of rabies virus in all available cattle brains began in 2010 .

Figure 3 depicts the spatial and temporal distribution of the rabies outbreaks during this period, as well as the geographical location of cattle farms throughout Costa Rica. Exact georeferencing was available for 64 of the 78 outbreaks $(82 \%)$. Six of the missing farm coordinates were estimated

Table 2. Year, Origin, and Mode of Transmission of Human Rabies Deaths in Costa Rica 1986-2014

\begin{tabular}{llccc}
\hline Year & Assumed origin & Fatalities & Suspected mode of transmission & Virus variant \\
\hline 2014 & Autochthonous & 1 & Squirrel & D. rotundus \\
2014 & Imported & 1 & Oppossum & Dog \\
2001 & Autochthonous & 2 & Cat & D. rotundus \\
$1994^{\mathrm{a}}$ & Imported & 1 & Unknown & Unknown \\
\hline
\end{tabular}

\footnotetext{
${ }^{\mathrm{a}}$ No further data available for this case.
} 
Table 3. Cattle Density and Rabies Outbreaks Per Province

\begin{tabular}{lcccc}
\hline Province & $\begin{array}{c}\text { No. of } \\
\text { cattle }\end{array}$ & $\begin{array}{c}\text { Cattle } \\
\text { density } \\
(\text { cattle/km }\end{array}$ & $\begin{array}{c}\text { No. of } \\
\text { outbreaks }\end{array}$ & $\begin{array}{c}\text { Total } \\
\text { outbreaks } \\
(\%)\end{array}$ \\
\hline Alajuela & 621,868 & 63.7 & 13 & 16.7 \\
Guanacaste & 416,728 & 41.1 & 15 & 19.2 \\
Puntarenas & 353,829 & 31.4 & 31 & 39.7 \\
Limón & 239,966 & 26.1 & 5 & 6.4 \\
San José & 154,259 & 31.1 & 9 & 11.5 \\
Heredia & 106,936 & 40.2 & 3 & 3.8 \\
Cartago & 73,138 & 23.4 & 2 & 2.6 \\
Total & $1,966,724$ & 38.5 & 78 & 100 \\
\hline
\end{tabular}

using the farm identification number from the SIREA database and eight through the use of Google Earth.

No statistical association was determined between cattle density and the number of outbreaks, at either provincial or cantonal level. The majority of outbreaks (almost 40\%) were observed in the province of Puntarenas, which has the fourth highest density of cattle (Table 3 ).

The time series as depicted in Figure 4 demonstrates the endemic situation and the relatively regular outbreaks of bovine rabies in Costa Rica. In some years, up to six outbreaks were registered, with an average of two to three outbreaks per year. No outbreaks occurred in five specific years.

Using moving averages of the squared frequencies (Fig. 5) allows a certain periodicity of outbreaks to be observed; however, the time period is not long enough to make serious predictions about the length of an outbreak cycle.

An average outbreak resulted in the death of less than 10 head of cattle (median 4). Two massive outbreaks were recorded in 1985 and 2003, resulting in the death of more than 100 head of cattle each time. Although far more outbreaks occurred in the Pacific region, the outbreaks in the Atlantic region involved more dead animals (452 vs. 271, respectively).

The majority of rabies outbreaks occurred at low altitudes (Fig. 6). A total of $82.0 \%$ of the outbreaks occurred between 0 and 500 meters above sea level, corresponding to the altitude of $65.7 \%$ of all cattle farms.
Dividing the country according to rainfall patterns into an Atlantic (including the provinces of Alajuela, Heredia, and Limón and Cartago) and a Pacific region (Guanacaste, Puntarenas, Cartago, and San José) reveals that $70.5 \%$ of the outbreaks have occurred in the Pacific region, and significantly more cattle rabies outbreaks could be observed in the rainy compared to the dry season $(p=0.04)$. No seasonal effect could be found in the Atlantic region (Table 4).

\section{Discussion}

The aim of this study was to provide an overview of the rabies situation in Costa Rica between 1985 and 2014, with particular emphasis on bovine outbreaks. Although progress has been made in Costa Rica with respect to canine rabies through control programs and vaccination, bovine rabies will remain endemic in the country, as bats are both the reservoir host and vector of the disease.

Vaccination of cattle is currently the only possible and recommended prevention method (Anderson et al. 2014), however, it is expensive to implement. At present, SENASA offers free vaccinations around an outbreak area. If the whole Costa Rican cattle population were vaccinated, vaccine costs alone would account for an estimated 3 million US dollars per year. Furthermore, this rough estimate does not include the costs of transport, cold storage, personnel, etc. and such a nationwide program, therefore, seems unrealistic. However, the data described here could be used to identify high-risk areas (such as the province of Puntarenas) and perform a costbenefit analysis to highlight areas where preemptive rabies vaccination might be beneficial. Since November 2015, cattle rabies vaccines in Costa Rica no longer require a veterinary prescription, but can be bought over the counter, which will make it easier for farmers to vaccinate their animals should they choose to do so.

Between 1985 and 2014, outbreaks occurred sporadically throughout the country. This indicates the disease's enzootic maintenance in Costa Rica with local multiannual cycles, as described in the literature (Streicker et al. 2012). The outbreak intensity has increased slightly during the last decade and in particular over the last 5 years (2010-2014). One

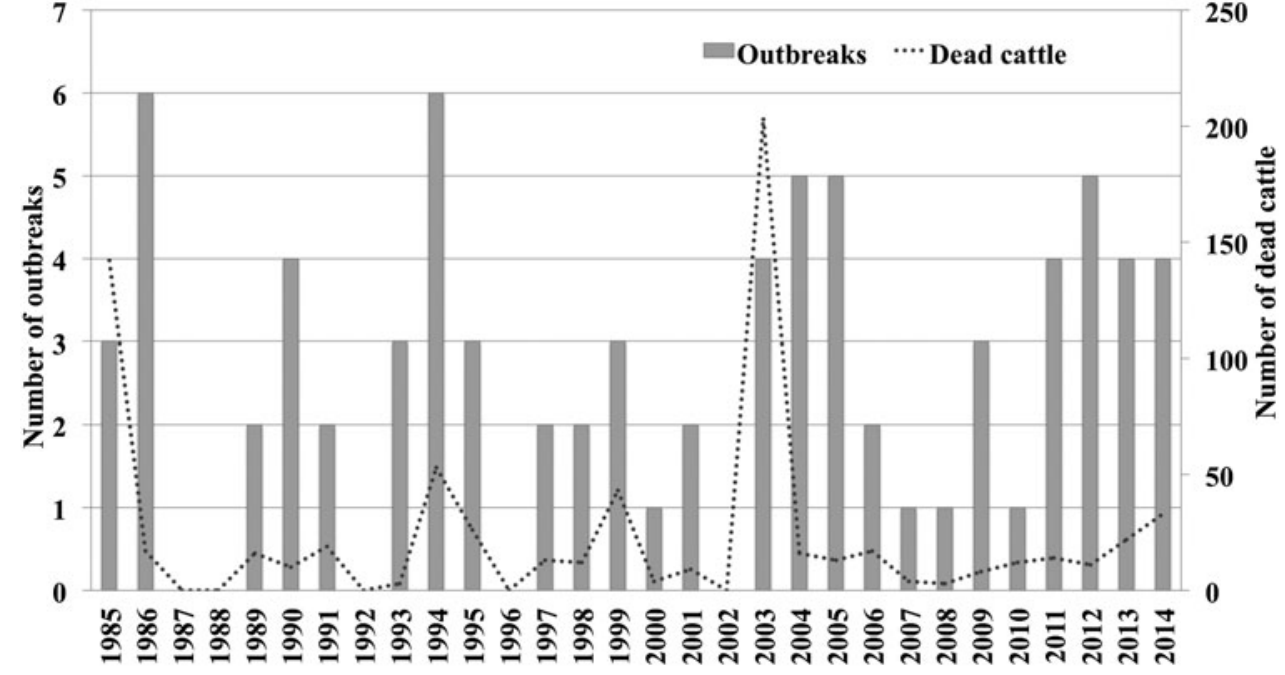

FIG. 4. Number of outbreaks and dead cattle 19852014. 
FIG. 5. Squared number of outbreaks with moving averages of four years.

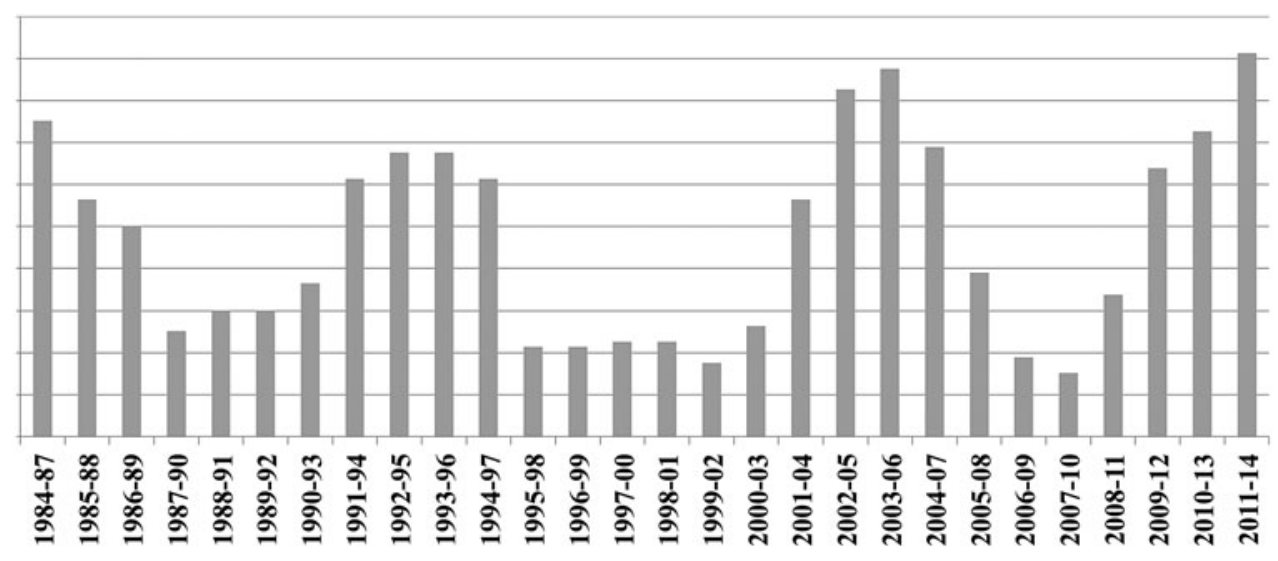

possible explanation for this increase is that from 2011, the number of submissions for testing has increased considerably due to the intensification of the syndromic surveillance for bovine spongiform encephalopathy.

The highest number of outbreaks $(39.7 \%)$ occurred in the province of Puntarenas. Vampire bats may find their preferred habitat in this part of the country, with its equatorial monsoonal and humid climate. While Puntarenas has a relatively average cattle density $\left(31.4 \mathrm{head} / \mathrm{km}^{2}\right)$ for Costa Rica, it also contains several national parks and conservation areas that provide undisturbed and protected refuges for vampire bats. The number of bovine rabies outbreaks reported here correspond with a Brazilian study which showed that vampire attacks occurred more frequently in areas of forest fragments close to cattle grazing areas (Gomes et al. 2010). Furthermore, a study in Guatemala reported that vampire bats are highly territorial with respect to feeding grounds and likely to visit the same cattle pastures, and even the same animals, frequently (Gilbert et al. 2015).

The distribution of $D$. rotundus is known to be influenced by temperature, as this bat species occurs in areas with the minimum temperature of $10^{\circ} \mathrm{C}$ ( $\left.\mathrm{McNab} 1973\right)$. In Southeast Brazil, many vampire bats were found to migrate to warmer areas during the cooler period, and temperature appears to be an important factor in bat behavior (Trajano 1996). In Costa Rica, the preference of $D$. rotundus for warmer temperatures may be a reason why $82.0 \%$ of the outbreaks occurred at altitudes below 500 meters.

Seasonality of rabies infections has been observed in bat surveillance in the United States (Patyk et al. 2012), but has also been found in other species, such as foxes in Alaska (Kim et al. 2014) or cattle and dogs in Bhutan (Tenzin Dhand et al. 2011).

We found significantly more outbreaks in the Pacific region during the rainy than during the dry season, while there was no difference in the number of outbreaks in the continuously wet Atlantic region. The higher number of outbreaks during the Pacific rainy season agree with a study in Argentina, where the influx of young susceptible bats during the rainy season was observed to coincide with rabies outbreaks in cattle (Lord 1992). While data regarding vampire bat ecology in Costa Rica are limited, a number of historical studies do exist. Vampire bat births were reported to have occurred throughout the year at a cattle ranch in the Pacific region of the country (Wilkinson 1990), although Turner (1975) had previously found a significant increase in pregnant and/or lactating females during the wet season at the same site. In contrast, in a study on the Atlantic region of Costa Rica, Young (1971) found that births do not occur throughout the year, but are concentrated in the 2 months just before heavier rains.

Outbreaks in the Atlantic region caused more cattle death than outbreaks on the Pacific side. A possible explanation for this higher number of cattle deaths and also the higher number of outbreaks in the Pacific rainy region might be related to the fact that longer periods of rainfall prevent bats from foraging. A study in Costa Rica showed that fewer bats leave their roost during the rainy than during the dry season (Young 1971). Bats are very sensitive to food deprivation, and two and three nights of fasting can be fatal (Freitas et al. 2003). Between $7 \%$ and $30 \%$ of bats are unable to nourish
FIG. 6. Altitude distribution of cattle farms (a), Desmodus rotundus observations (b) and bovine rabies outbreaks (c) in Costa Rica between 1985-2014.

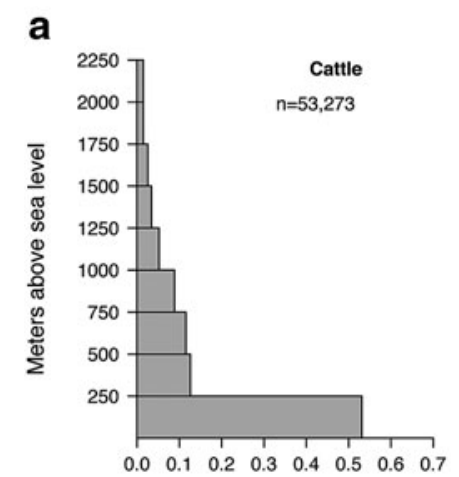

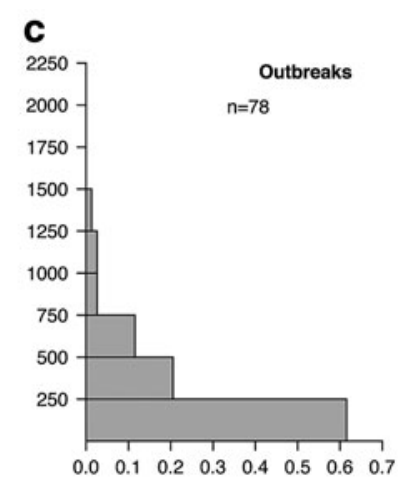


Table 4. Seasonal Distribution of Cattle Rabies Outbreaks on Atlantic and Pacific Side of Costa Rica (and Chi-Square Results)

\begin{tabular}{lccccc}
\hline Region & \multicolumn{1}{c}{ Provinces } & Season & Month $^{\mathrm{a}}$ & Observed $^{\mathrm{a}}$ outbreaks & Results $^{\mathrm{b}}$ \\
\hline \multirow{2}{*}{ Atlantic } & Limón, Heredia, Alajuela, Cartago & Rainy & $1,4,5,6,7,8,11,12$ & 13 & $p=0.598$ \\
& & Drier & $2,3,9,10$ & 9 & $\mathrm{df}=1$ \\
Pacific & Puntarenas, Guanacaste, San José & Rainy & $5,6,7,8,9,10,11^{\mathrm{c}}$ & 40 & $p=0.043$ \\
& & Dry & $1,2,3,4^{\mathrm{c}}, 12$ & 15 & $\mathrm{df}=1$ \\
\hline
\end{tabular}

${ }^{\mathrm{a}}$ Months are numbered according to their calendar sequence.

${ }^{\mathrm{b}}$ For one of the 78 outbreaks, the month was missing and therefore this outbreak was not included in the calculations.

${ }^{\mathrm{c}}$ Transition month.

themselves on any given night, but they may receive regurgitated blood either from a kin or a roosting mate (Wilkinson 1990). Whether food deprivation or blood meal regurgitation has an effect on rabies transmission is currently unclear, and more research on vampire bat immunity is needed to provide possible explanations as to why more rabies outbreaks were reported in the rainy season.

The Costa Rican veterinary authority, SENASA, has only recently started virus typing, but the initial evidence shows that of five cattle outbreaks analyzed since 2014, four were associated with vampire bat rabies strains. One rabies outbreak, however, was a $T$. brasiliensis strain. Although T. brasiliensis has been reported to commonly be infected with the virus in the Americas (Patyk et al. 2012, Escobar et al. 2014), this finding is important, as it is the first report in Costa Rica of rabies transmission through a virus strain commonly associated with this insectivorous bat species. It could not be determined how this bovine animal became infected with this strain. One or two more animals had died with similar clinical signs on the farm several months beforehand, but these cases had not been reported to the veterinary authorities at the time and therefore could not be confirmed as rabies cases.

As is common in retrospective studies, a number of limitations with respect to data quality were observed. It is important to note that the veterinary authorities may not have been notified of all outbreaks (underreporting must be assumed, since investigations of surrounding farms occasionally determined more animals having died after exhibiting similar clinical signs). On the other hand, it is also possible that not all dead cattle registered in an outbreak are actually rabies related. Ideally, accurate quantitative data should be collected on the number of farms as well as age, breed, and clinical signs of animals involved in each outbreak. In the past, such data collection was difficult and labor intensive, however, new surveillance software should help remedy this situation. Reports have been made of problems with cold storage and transportation of samples throughout Latin America (Gilbert et al. 2015), and it is likely that such issues also occurred during the early years of rabies surveillance covered here. In addition, it would be ideal to confirm all suspected rabies cases in individual animals by laboratory analysis and perform a phylogenetic sequence analysis for each outbreak. Our work also demonstrated the limited amount of data available on vampire bat ecology in Costa Rica. Additional data on vampire bat distribution, abundance, migration, and seasonal behavior, as well as the level of rabies virus infection among these populations, should also be collected to allow for more accurate assessments of disease transmission routes. A first step would be to record more biometric data such as bat species, sex, age, and weight on wildlife submissions for rabies testing in general and on bat submissions in particular. Ideally, rabies surveillance in wildlife should be intensified overall.

\section{Conclusions}

This is the first comprehensive epidemiological analysis of bovine rabies in Costa Rica. Data included here demonstrate that the disease in Costa Rica was primarily found in cattle, which are dead-end hosts, and is present in wildlife, particularly in vampire bats, which act both as the main reservoir and vector of the bovine disease. In domestic livestock other than cattle, the disease was diagnosed at a very low level of incidence. While human cases are extremely rare in Costa Rica (three autochthonous cases in the recorded 30-year time period), given the virus' zoonotic characteristics and fatal outcome among cattle and humans, it is extremely important for public health services to be aware of the potential for sporadic cross-species transmission: all three human fatalities were linked to animal species (cat, squirrel) not expected by public health authorities to transmit the disease. The general population should be aware of the potential of rabies infection from bats, cattle, and other domestic and wildlife species, and public health services need to be mindful of the importance of adequate wound hygiene and postexpositional rabies prophylaxis when dealing with both wild and domestic animal bites.

Rabies outbreaks are expected to continue in Costa Rica. An improved surveillance plan with particular emphasis on wildlife, the continued sequencing of rabies outbreaks, studies on bat ecology, and a cost-benefit analysis on preemptive vaccination should all be considered to contribute to the understanding, and, subsequently, to improve the control of rabies transmission in Costa Rica.

\section{Acknowledgments}

We would like to thank the Ministry of Agriculture and Livestock of Costa Rica, as well as SENASA director Dr. Bernardo Jaen and deputy director Dr. Alexis Sandí for making this study possible. Furthermore, we would like to acknowledge all SENASA officials who have attended rabies outbreaks and collected and diagnosed samples throughout this 30-year period.

\section{Author Disclosure Statement}

No competing financial interests exist. 


\section{References}

Anderson A, Shwiff S, Gebhardt K, Ramírez AJ, et al. Economic evaluation of vampire bat (Desmodus rotundus) rabies prevention in Mexico. Transbound Emerg Dis 2014; 61:140 146.

Badilla X, Pérez-Herra V, Quirós L, Morice A, et al. Human rabies: A reemerging disease in Costa Rica? Emerg Infect Dis 2003; 9:721-723.

Belotto A, Leanes LF, Schneider MC, Tamayo H, et al. Overview of rabies in the Americas. Virus Res 2005; 111:5-12.

Delprieto HA, Marchevsky N, Simonetti E. Relative population densities and predation of the common vampire bat (Desmodus rotundus) in natural and cattle-raising areas in northeast. Prev Vet Med 1992; 14:13-20.

Ellison JA, Gilbert AT, Recuenco S, Moran D, et al. Bat rabies in Guatemala. PLoS Negl Trop Dis 2014; 8:e3070.

Escobar LE, Restif O, Yung V, Favi M, et al. Spatial and temporal trends of bat-borne rabies in Chile. Epidemiol Infect 2014; 143:1486-1494.

Freitas MB, Welker AF, Millan SF, Pinheiro EC. Metabolic responses induced by fasting in the common vampire bat Desmodus rotundus. J Comp Physiol B Biochem Syst Environ Physiol 2003; 173:703-707.

GBIF. Free and open access to biodiversity data. Glob Biodivers Inf Facil. 2015. Available at www.gbif.org.

Gilbert A, Greenberg L, Moran D, Alvarez D, et al. Antibody response of cattle to vaccination with commercial modified live rabies vaccines in Guatemala. Prev Vet Med 2015; 118:36-44.

Gomes MN, Monteiro AMV, Lewis N, Gonçalves CA, et al. Landscape risk factors for attacks of vampire bats on cattle in Sao Paulo, Brazil. Prev Vet Med 2010; 93:139-146.

Hijmans RJ, Cameron SE, Parra JL, Jones PG, et al. Very high resolution interpolated climate surfaces for global land areas. Int J Climatol 2005; 25:1965-1978.

Hoinville LJ, Alban L, Drewe JA, Gibbens JC, et al. Proposed terms and concepts for describing and evaluating animalhealth surveillance systems. Prev Vet Med 2013; 112:1-12.

Instituto Metereológico Nacional. Segunda comunicación nacional: Clima, variabilidad y cambio climático en Costa Rica. San José, Costa Rica, 2008.

Instituto Nacional de Estadísticas-INEC. VI Censo Nacional Agropecuario. San José, Costa Rica, 2015.

IUCN, UNEP-WCMC. The World Database on Protected Areas (WDPA). 2014. Available at www.protectedplanet.net.

Johnson N, Aréchiga-Ceballos N, Aguilar-Setien A. Vampire bat rabies: Ecology, epidemiology and control. Viruses 2014; 6:1911-1928.

Kim BI, Blanton JD, Gilbert A, Castrodale L, et al. A conceptual model for the impact of climate change on fox rabies in Alaska, 1980-2010. Zoonoses Public Health 2014; 61:72-80.

Lord RD. An ecological strategy for controlling bovine rabies through elimination of vampire bats. Proceedings of the 9th Vertebrate Pest Conference, Fresno, California, 1980: 3-4.

Lord RD. Seasonal reproduction of vampire bats and its relation to seasonality of bovine rabies. J Wildl Dis 1992; 28:292-294.

Loza-Rubio E, Aguilar-Setién A, Bahloul C, Brochier B, et al. Discrimination between epidemiological cycles of rabies in Mexico. Arch Med Res 1999; 30:144-149.
Mayen F. Haematophagous bats in Brazil, their role in rabies transmission, impact on public health, livestock industry and alternatives to an indiscriminate reduction of bat population. J Vet Med 2003; 50:469-472.

McDaniel CJ, Cardwell DM, Moeller RB, Gray GC. Humans and cattle: A review of bovine zoonoses. Vector Borne Zoonotic Dis 2014; 14:1-19.

$\mathrm{McNab}$ B. Energetics and the distribution of vampires. J Mammal 1973; 54:131-144.

Ministerio de Salud. Rabia. Protocolo de vigilancia y control en humanos. San José, 2014.

Patyk K, Turmelle A, Blanton JD, Rupprecht CE. Trends in National Surveillance Data for bat rRabies in the United States: 2001-2009. Vector Borne Zoonotic Dis 2012; 12:666673.

R Core Team. R: A language and environment for statistical computing. Vienna, Austria, 2014. Available at: http://www .r-project.org

Rupprecht CE, Kuzmin IV. Why we can prevent, control and possibly treat-But will not eradicate-Rabies. Future Virol 2015; 10:517-535.

SENASA. SIREA (Sistema Integrado de Registro de Establecimientos Agropecuarios). 2014. Available at http:// registrosenasa2.addax.cc/

Streicker DG, Recuenco S, Valderrama W, Gomez Benavides J, et al. Ecological and anthropogenic drivers of rabies exposure in vampire bats: Implications for transmission and control. Proc Biol Sci 2012; 279:3384-3392.

Tenzin Dhand NK, Ward MP. Patterns of rabies occurrence in Bhutan between 1996 and 2009. Zoonoses Public Health 2011; 58:463-471.

Trajano E. Movements of cave bats in Southeastern Brazil, with emphasis on the population ecology of the common vampire bat, Desmodus rotundus (Chiroptera). Biotropica 1996; 28: 121-129.

Turner DC, 1975. The Vampire Bat-A Field Study in Behaviour and Ecology. Baltimore and London: John Hopkins University Press, 1975:101-111.

Voigt CC, Kelm DH. Host preference of the common vampire bat (Desmodus rotundus; Chiroptera) assessed by stable isotopes. J Mammal 2006; 87:1-6.

WHO. WHO Expert consultation on rabies-Second Report, World Health Organization technical report series. Geneva, Switzerland, 2013.

Wilkinson GS. Food sharing in vampire bats. Sci Am 1990; 262:64-70.

Young AM. Foraging of vampire bats (Desmodus rotundus) in Atlantic wet lowland Costa Rica. Rev Biol Trop 1971; 8:73-88.

Address correspondence to: Sabine E. Hutter Institute of Veterinary Public Health University of Veterinary Medicine Veterinaerplatz 1 Vienna 1210 Austria

E-mail: sabine.hutter@vetmeduni.ac.at 